\title{
Polymer Characterization by Combined Chromatography-Infrared Spectroscopy
}

\author{
James L. Dwyer and Ming Zhou \\ Spectra Analysis Instruments, Inc., 257 Simarano Drive, Marlborough, MA 01752-3070, USA \\ Correspondence should be addressed to James L. Dwyer, dwyerpadre@gmail.com
}

Received 3 May 2011; Revised 25 July 2011; Accepted 21 August 2011

Academic Editor: Ahmed Aamouche

Copyright ( $) 2011$ J. L. Dwyer and M. Zhou. This is an open access article distributed under the Creative Commons Attribution License, which permits unrestricted use, distribution, and reproduction in any medium, provided the original work is properly cited.

Infrared spectroscopy is widely used in the analysis and characterization of polymers. Polymer products are not a singular species, but rather, they are a population of polymer molecules varying in composition and configuration plus other added components. This paper describes instrumentation that provides the benefit or resolving polymer populations into discrete identifiable entities, by combining chromatographic separation with continuous spectra acquisition. The technology also provides a way to determine the mass distribution of discrete components across the chromatographic distribution of a sample. Various examples of application of this technology to polymer products are described. Examples include additives analysis, resolution of polymer blends, composition characterization of copolymers, analysis of degradation byproducts, and techniques of analysis of reactive polymer systems.

\section{Introduction}

"The primary motivation for determining the structure of a polymer chain is to relate the structure to the performance properties of the polymer in end use. If a polymer chain is completely characterized and the structural basis of its properties is known, the polymerization can be optimized and controlled to produce the best possible properties from the chemical system" $[1]$.

This paper addresses hyphenated chromatography-IR spectrometry instrumentation and the data processing and presentation techniques that can reveal the compositional and molecular structural properties of polymer materials.

In analysis of polymers, no single technique can provide as much information as can Fourier transform infrared spectrometry (FTIR). Many commercial polymer products are not simply a single homopolymer, but rather are multicomponent systems. To obtain maximum information regarding the product, one must utilize some fractionation process prior to spectroscopy.
Polymer products are quite complex. They may consist of mixtures of discrete components. The polymerization process typically yields variations in structure and composition as polymerization proceeds. These variations dictate the physical properties (strength, flexibility, melting point, and glass transition temperatures, to name a few) in the resulting product. In some cases, it is desirable to have invariant structure and composition throughout the population of polymer chains, while in other cases, such variations are specifically generated by the manipulation of the polymerization process. Characterization of distributed composition and structural properties, therefore, is essential to physical properties optimization and control. This paper offers a number of examples demonstrating the utility of this technology.

\section{Hyphenated Chromatography-FTIR Spectrometry: Technology and Instrumentation Description}

Note. The use of the word "peak" refers to a chromatogram. "Band" is used in describing infrared spectral bands. 
A limitation of classical infrared spectroscopy is the inability to characterize or identify components in a mixture. Chromatography is a powerful tool for resolving/ separating solutes, but provides no molecular identification of solute components. Liquid Chromatography-FTIR (LCFTIR) addresses this limitation by chromatographic separation of mixed solutes coupled to a spectrometer which processes the eluting resolved constituents and acquires their discrete spectra. This publication illustrates the use of hyphenated LC-FTIR to provide graphical and numeric information regarding multicomponent samples.

A hot-melt adhesive was analyzed by gel permeation chromatography-FTIR (GPC-FTIR). A sample was injected onto a suitable chromatographic column, and the column eluant passed to a continuous sample collecting module containing an FTIR spectrophotometer. The sample chromatogram is effectively "painted" onto an IR transparent medium as a continuous stripe of solutes eluate. Sequential spectra collected along this stripe are the basis of a timearrayed data set of sample composition as a function of elution time.

Figure 1 shows chromatographic and spectral data obtained from a data set. The uppermost graphic is an infrared chromatogram of the deposited sample $\mathrm{C}-\mathrm{H}$ stretch bands of the sample. Below that are specific elution time spectra of the discrete components. By choosing spectral bands that are unique to each solute, one can see and measure the distribution of the individual solute components across the elution profile, even when those components may not be chromatographically resolved. In one integrated procedure, GPCFTIR can provide molecular/structural characterization of complex multicomponent samples. This paper presents a number of examples of polymer characterizations, focusing on the data processing techniques to show composition and distribution of various multicomponent polymeric samples.

There have been numerous developments of instrumentation that could provide LC-FTIR capability. Two fundamental approaches have emerged: (1) flow cells and (f2) solvent elimination systems. The flow-cell approach, analogous to ubiquitous LC-UV (liquid flow cell detectors operating in the ultraviolet range) systems, has limited utility when applied to LC-IR. The latter has poor detection limits, due to limited optical path length and to interfering IR bands generated by the LC mobile phase. There is several thousand times as much mobile phase, as there is solute in the flow cell during the elution, and any absorbance by the mobile phase will swamp the sample in spectral regions, where the mobile phase has any IR absorbance. As a result, flow cells can be utilized only for the spectral regions in which the mobile phase exhibits no absorbance. LC-IR flow cell methods have been used for polymers that possess structure that manifests itself in such solvent spectral window regions, but they typically require complex chemometric statistical methods to determine composition based on the severely limited spectral regions available. Short-chain branching in polyolefins is measured via LC-FTIR using flow cell methods. Recently, the structural characterization of polycarbonates was reported, utilizing 2-dimensional chromatography, flow

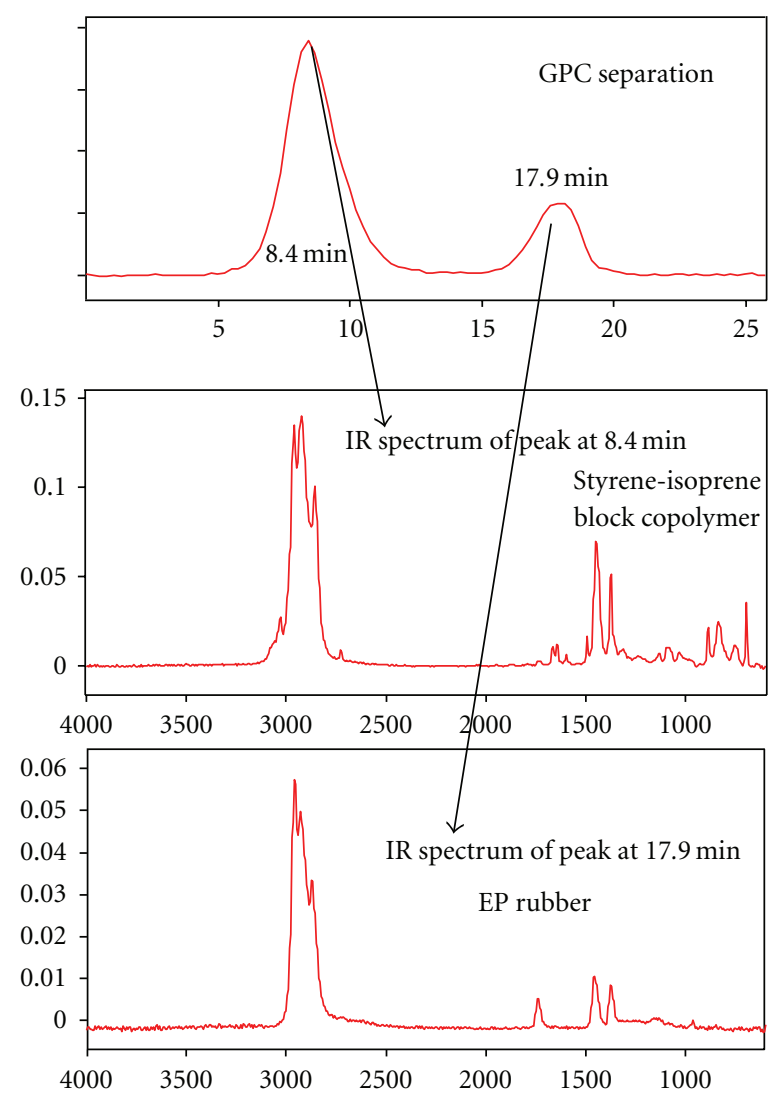

Figure 1: Hot-melt adhesive components identification.

cells, and multivariate statistical analysis of the raw data mass [2] (an extremely time-consuming, complex methodology).

Most of the instrumentation development has centered on solvent elimination processes. Some solvent elimination devices made use of microbore chromatography columns which would deposit eluant droplets into wells on a moving plate, which could, after evaporation, yield reflectance or transmission spectra. It was apparent that the use of nozzle systems could be used for evaporative removal of eluant, depositing the solutes as dry solids. Bieman and Gagel developed an instrument that directed column eluant through a pneumatic nebulizer, depositing the nonvolatile solutes onto the surface of a slowly revolving germanium disk as regular track [3, 4]. Griffiths et al. [5] achieved subnanogram sensitivity by use of microbore columns and a glass capillary nebulizer operating in an evacuated chamber. Dekmesian [6] extended applications of solute deposition to mobilephase solvents of very high boiling point, such as trichloro benzene, a mobile phase regularly used in chromatography of polyolefins. He achieved adequate evaporative capacity by using a combination of ultrasonic nebulization, high vacuum, and high temperatures within the solute deposition chamber.

\section{Equipment}

Figure 2 shows the principal components of the system (The DiscovIR, Spectra Analysis Instruments, Inc.). At the right is 


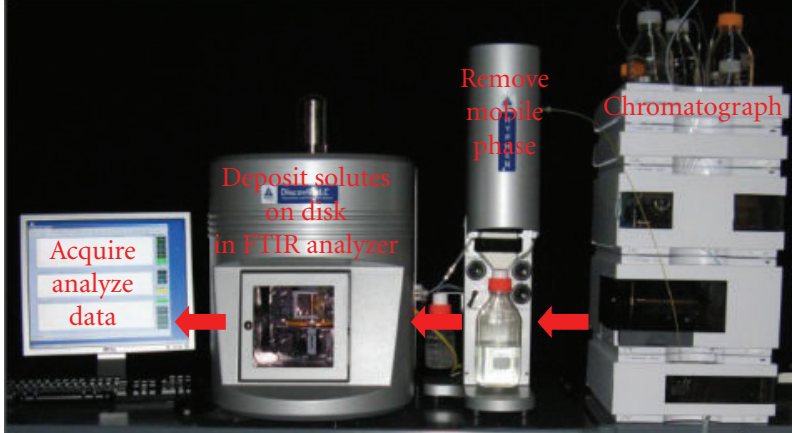

FIGURE 2: DiscovIR HPLC-IR analyzer.

an unmodified HPLC system. Column eluant flows to a unit that nebulizes the solutes and evaporates the liquid mobile phase from the eluate. The nebulized solute particles and solvent vapor then pass to a cooling section that condenses solvent vapor and drains it to a waste bottle. Solutes are propelled by a combination of carrier gas and residual solvent vapor to a nozzle located above the surface of the IR transparent $\mathrm{Zn}$ Se disk. A small proportion of the solvent remains with the nebulized solute particles, thereby providing some cohesion to the deposit track. In the high vacuum environment of the deposition chamber, residual solvent flashes off the deposited solute prior to the deposit passing through the FTIR energy beam. The nebulization apparatus is autoregulating and readily accommodates solvent gradient LC protocols. Carrier gas, disk temperature, and chamber vacuum controls serve to optimize the nozzle deposition process, and solvent elimination.

In polymer work gel permeation chromatography (GPC) is most commonly employed, but other chromatography modes, such as reverse-phase, work quite satisfactorily. Unlike HPLC-IR flow cells, this type of interface eliminates all chromatography mobile phase and has none of the spectral interference limitations encountered in use of chromatography-IR flow cells.

With the exception of the IR chromatograms shown in Figure 15, all GPC chromatograms are shown simply as elution time. When a molecular weight (MW) axis is desired, one can apply a scale transform to the data set, or the time axis of the chromatogram. Calibration is done with conventional GPC methods, employing appropriate calibration standards.

An overall schematic is shown in Figure 3. The source infrared energy is focused on the solute track, and the transmitted IR beam passes to the detector of a Fourier transform interferometer. The interferometer generates a spectrum every 0.5 seconds and stores acquired IR spectra as a time-ordered data set. Spectral resolution is a selectable parameter. For the cited examples, a spectral resolution of $8 \mathrm{~cm}^{-1}$ was employed. To improve signal/noise ratio and short range smoothing of the solid-phase solute deposit of the single scan spectra, a triangular weighted moving average is optionally used, typically with thirty scans/averaged for each data pint.

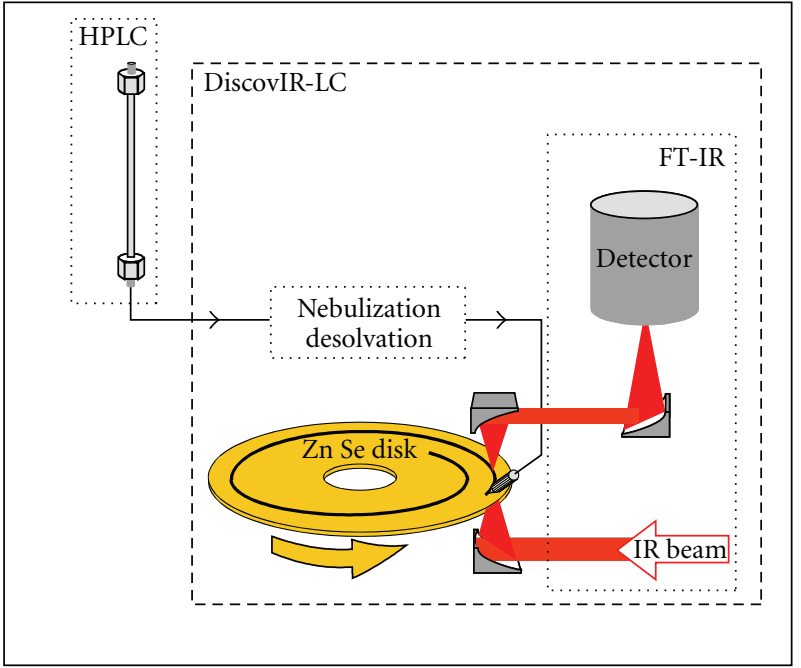

FIGURE 3: Instrument schematic representation.

Instrument automated operation and data analysis is provided by software resident on a dedicated computer. The system has all the functionality associated with FT-IR bench instruments, and including spectral library capabilities.

Equipment utilized for LC-FTIR polymer analysis is shown in Figure 2. A single computer using a Windows operating system and customized Galactic/Grams software serves for both control of sample runs and data analysis. The software encompasses a powerful array of data processing algorithms and display modes for single spectra and multiple file data sets. Most applications utilize molecular weight separation as the chromatography step, but other chromatography modes, such as reverse-phase chromatography and critical condition solvent chromatography, can be readily applied.

\section{Application Examples}

This presentation focuses on the techniques of utility in extracting compositional information from LC-IR of various polymeric materials. For experimental parameters used in these analyses, please refer to the Section 5 near the end of the presentation. Applications of the following types are illustrated throughout the content of this publication. A useful way to categorize type of applications is shown in Table 1.

The "hyphenation" of liquid chromatography with Infrared spectroscopy provides the opportunity to resolve multicomponent samples and contain spectral information about the individual components. In the case of polymers, one can reveal changing composition/configuration of polymer molecules across the molecular weight distribution. Applications described include polymer characterizations based on composition, configuration, and conformation of polymer molecules.

(i) "The composition of a molecule defines the nature of the atoms and their type of bonding irrespective of their spatial arrangement. 
TABLE 1: Polymer industry GPC-FTIR application types.

(i) Components identification

(ii) Deformulation

(iii) Reactive systems analysis (i) Copolymers: comonomer distribution

(ii) Aging/environmental changes

(iii) Lot-to-lot characterization "good versus bad" (ii) The configuration of chemical groups characterizes a chemical state of a molecule. Different configurations constitute different chemical individuals and cannot be converted into one another without rupture of chemical bonds.

(iii) The conformation of chemical groups characterizes the geometrical state of a molecule. Different conformations of a molecule can be produced by rotation about single bonds without rupture of chemical bonds. Changes in conformation arise from physical considerations such as temperature, pressure, or stress and strain" [7].

4.1. Deformulation: Analysis of Lubricant Polymeric Additives. The following example is a characterization of poylymeric additives present in a heavy duty diesel engine lubricant. Petroleum-based motor oils are manufactured with a complex "additives package" that provide for optimal performance in the harsh operating environment of internal combustion engines. A significant fraction of motor oils consists of synthetic polymers. Functions of these polymers include viscosity-temperature modulation and the dispersion of sludge generated in the environment of an operating engine.

A sample of (unused) motor oil was injected onto a gel permeation chromatography (GPC) column which was coupled to a DiscovIR FTIR system. Figure 4 depicts the data collected from the higher molecular weight components of the oil sample. The $X$-axis is spectral frequency (wave number). The $Y$-axis is elution time, and the $Z$-axis is spectral absorbance. These early eluting components are high molecular weight and are solid-phase when deposited on the zinc selenide ( $\mathrm{Zn}$-Se) collection disk. The lubricant itself is liquid hydrocarbon oil, and at 12.2-minute elution time, a valve was actuated to divert column eluate from deposition on the collection disk.

Casual inspection of the deposit spectra indicate that the polymer material is made up of at least two components. The first elution material has an intensity maximum at 9.2 minutes, corresponding to a MW of 600 k Daltons Figure 5.

4.1.1. Identification of the First Elution Peak. Inspection of the spectrum yielded the following observations:

(i) typical aromatic $\mathrm{C}-\mathrm{H}$ stretches $\left(3082 \mathrm{~cm}^{-1}\right.$, $\left.3061 \mathrm{~cm}^{-1}, 3027 \mathrm{~cm}^{-1}\right)$,

(ii) ring breathing modes $\left(1601 \mathrm{~cm}^{-1}, 1493 \mathrm{~cm}^{-1}\right)$,

(iii) aromatic ring out of plane bends $\left(698 \mathrm{~cm}^{-1}\right.$, $\left.756 \mathrm{~cm}^{-1}\right)$,

(iv) $1735 \mathrm{~cm}^{-1}$ carbonyl,

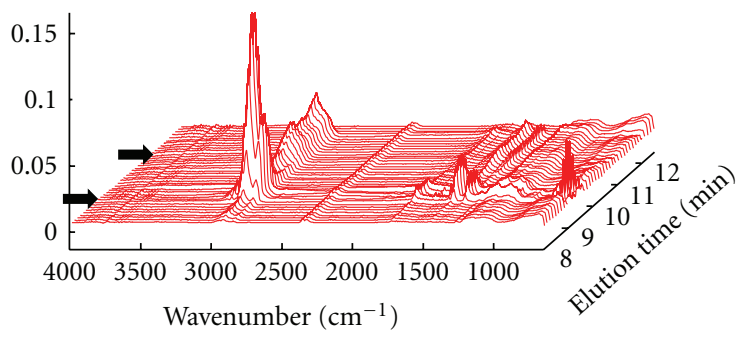

FIgURE 4: Time-ordered spectra from the GPCFTIR analysis of diesel motor oil.

(v) C-O stretches in the $1200-1000 \mathrm{~cm}^{-1}$ region,

(vi) bands associated with conjugated dienes are absent.

4.1.2. Identification of the Second Elution Peak. The spectra of this elution region are those of a styrene-acrylate copolymer. This is consistent with the viscosity index improvers used in engine lubricants.

The broad eluant profile in the 10-12 minute elution timeframe provided the spectrum in Figure 6. Spectra present the same bands across this region; indicating a homogenous chemistry, with a broad variation of molecular weight $(30,000-8000 \mathrm{mw})$. This spectrum is characteristic of the dispersant polyisobutenyl succinimide (PIBS). The broad elution profile of this material suggests a heterogeneity of molecular weight in this fraction, but no clear evidence of compositional drift in the comonomers. The ratio of bands $\left\{\right.$ dimethyl $\left(1367 \mathrm{~cm}^{-1}\right) /$ imide $\left.\left(1700 \mathrm{~cm}^{-1}\right)\right\}$ decreases by only about $10 \%$ across the elution time of $10.5-12.2 \mathrm{~min}$.

Note in the above spectra that a $700 \mathrm{~cm}^{-1}$ band is present only in the first solute peak. Similarly, a $1220 \mathrm{~cm}^{-1}$ band is present only in the second solute peak. The data analysis software that is incorporated with the instrument provides for the generation of infrared chromatograms of selected spectral bands. This powerful feature enables the analyst to generate a chromatogram that shows the distribution of a particular polymeric component even when the polymer components are not completely resolved chromatographically.

Figure 7, thus, reveals the molecular weight distribution chromatograms of both components. In large industrial applications, such as diesel powered railroad locomotives the level of these additives is monitored, and replenished as necessary to maintain performance of the lubricant.

4.2. Deformulation: Polymer Band Chromatograms. Polymer composition or configuration chromatograms can aid in the deformulation of complex systems. Figure 8 is an analysis of an automotive tire rubber formulation. In a similar manner, 


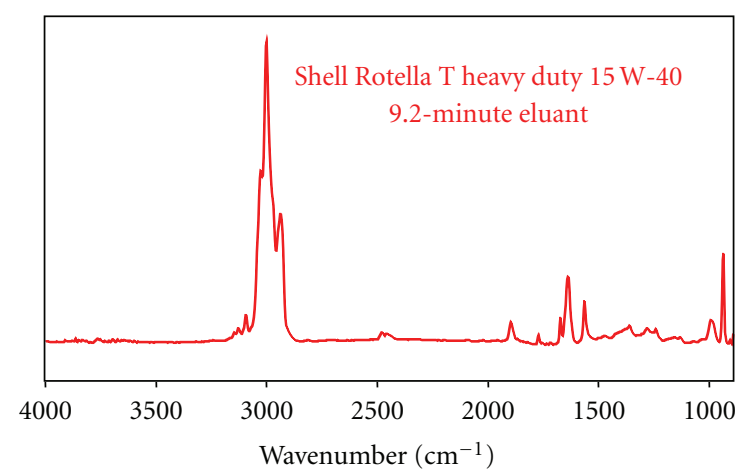

Figure 5: First elution peak spectrum.

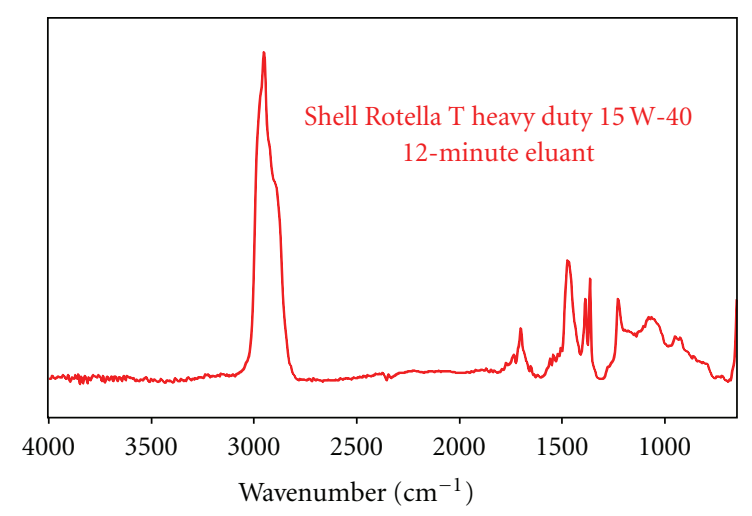

FIgURE 6: Second elution peak spectrum.

this sample was run on a GPC column, with tetrahydrofuran (THF) as the mobile phase. The sample is styrene-butadiene rubber (SBR) used in automotive tire manufacture, of which $150 \mu \mathrm{L}$ was injected at a concentration of $0.15 \%$ (wt./vol.).

Initial inspection of the data suggested a polymer or polymers containing (trans) butadiene and styrene. These styrene $\left(700 \mathrm{~cm}^{-1}\right)$ and diene $\left(967 \mathrm{~cm}^{-1}\right)$ chromatograms virtually overlap in shape and elution times. This indicates a styrene butadiene rubber (SBR) copolymer in which the ratio of the comonomers is invariant across the molecular weight distribution of the copolymer.

The third (maximum band intensity) chromatogram is generated from the $\mathrm{CH}$ stretch bands and closely corresponds to the total mass of solutes. Notice that there is a sharp rise in this IR chromatogram at 31 minutes, and that this elution profile extends to lower molecular weights than do the comonomers. Examination of a spectrum at 31 minutes elution time indicates a different composition than the copolymer.

The chromatogram of the $1707 \mathrm{~cm}^{-1}$ band has a completely different distribution from the SBR polymer. It elutes at the tail of the SBR profile and has a different spectrum. The $1700 \mathrm{~cm}^{-1}$ band is generated by a carbonyl of lower molecular weight additive, included with the polymer to promote cross-linking with other components that will be added to the final formulation. This illustrates the ability to deformulate or identify the discrete components that

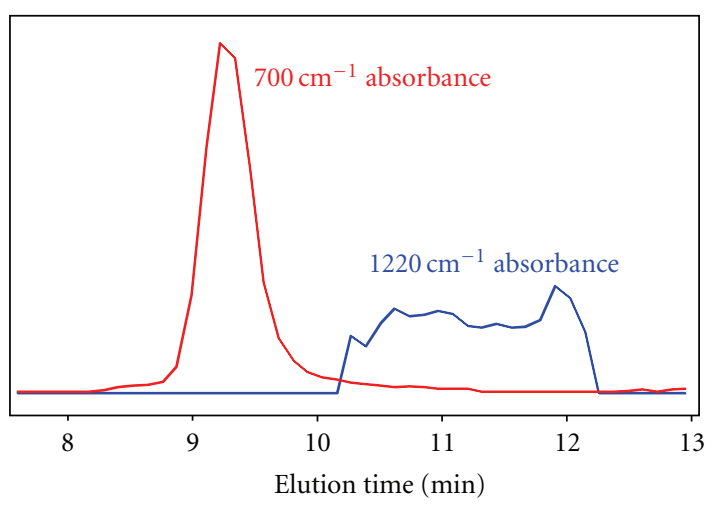

FIGURE 7: Infrared band chromatograms of the deposited sample.

comprise this sample. The technique can be applied to more complex samples by selecting spectral bands unique to each component.

4.3. Overlapping IR Chromatograms of Polymer Blends. In many, if not most, polymer blend samples, there is significant molecular weight overlap of the different polymer components. This example illustrates the data processing techniques used to characterize such solute overlaps.

This blend sample shows two polymers that have at least one pair of mutually exclusive bands. The uppermost in Figure 9 is the GPC-FTIR chromatogram of the sample. Two spectra are displayed, taken at the points indicated by the red and blue bars on the chromatogram. They show the differing spectra of the two components. A spectrum taken in the middle of this chromatogram would show the spectral Patterns of both solutes. Below are the infrared chromatograms at $1705 \mathrm{~cm}^{-1}$ and $1734 \mathrm{~cm}^{-1}$ bands Figure 10 .

The discrete mw weight distributions of each blend component are readily apparent. If one selects two spectra from the tails of the overall distribution, as in Figure 9, spectra of each component sufficient for identification can be obtained. Weighted spectral subtractions of one from the other will improve the spectral identification of each component. This is useful when spectral libraries are being used to aid identification.

4.4. Copolymers: Composition Drift. Copolymers are complex. During polymer synthesis the molecular population varies simultaneously in molecules size, concentration, and composition.

The reaction rates of the comonomers are seldom exactly equal. As a consequence the comonomer proportions will often change as polymerization proceeds. This is called "composition drift". Generally, composition drift will alter the finish physical properties of a copolymer. In some instance, the polymer chemist desires a minimum of composition drift, whilst in others a particular drift profile is deliberately sought [8-10]. Drift, therefore, must be determined and polymerization process controls (such as programmed stepwise addition of the monomers) [11] must be instituted to control composition drift, so as to achieve desired final properties of the copolymer product. 


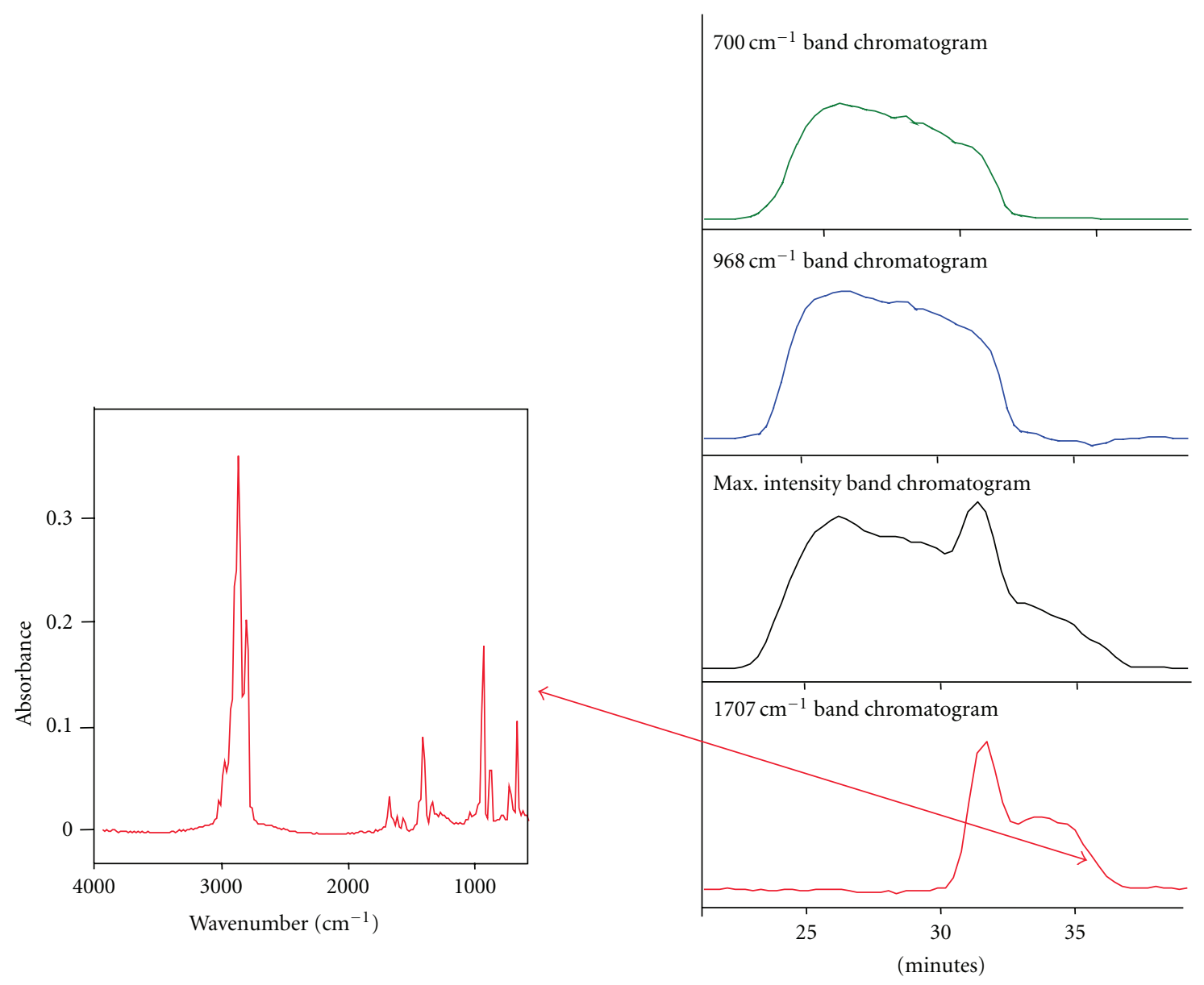

Figure 8: Tire polymer sample.

Typically, the total mass chromatogram of the polymer chains resembles a probability distribution plot-at a maximum in the region of the average molecular weight, and tapering off to nothing at the high and low molecular weight extremes of the distribution. Both the total mass and comonomer concentration are varying across the GPC elution profile. At any point in the chromatographic elution, a comonomer spectral band intensity is a product of the instantaneous elution mass and the per cent concentration of the comonomer.

Figure 11 illustrates conceptually the simultaneous variation in molecular weight and comonomer composition. Hyphenated GPC-FTIR analysis provides a very useful technique to measure composition drift in copolymer synthesis. The following example is an analysis of composition drift in a copolymer of styrene and (trans)butadiene.

This is the bulk spectrum of the copolymer. Useful IR bands for determination of composition are color highlighted. The (trans)butadiene is the green band, and the three styrene bands are highlighted in red Figure 12.

Figure 13 shows the time-ordered spectra of the fingerprint region of the copolymer spectra. The strongest absorption bands of the comonomers are indicated.

Assuming that the deposited chromatogram conforms to the Lambert-Beer law of band absorbances, the absorbance of a spectral band at any place along the elution curve is equal to the product of the band extinction coefficient the solute deposit thickness, and the concentration of the comonomer in the copolymer

$$
\mathrm{A}_{v i}=\varepsilon_{v i} b \mathrm{C}_{i},
$$

where $\mathrm{A}_{v i}$ is the absorbance of component $i$ at wavenumber $\nu, \varepsilon_{v i}$ is the molar absorptivity of component $i, b$ is the film thickness, $C_{i}$ is the fraction of component $i$ in the FTIR sample beam, and ratio chromatogram is $A_{v 1} / A_{v 2}$

$$
\text { Bands Ratio }=\frac{A_{v 1}}{A_{v 2}}=\frac{\varepsilon_{v 1} \cdot C_{1}}{\varepsilon_{v 2} \cdot C_{2}}=k \frac{C_{1}}{C_{2}} .
$$

Equation (2) has the effect of cancelling out the varying deposited mass " $b$ " across the elution profile. The value of the absorbance ratio at all points is dictated simply by the comonomers extinction coefficients and their respective concentrations. It can be seen that there is a considerable composition variation with high concentrations of styrene comonomer in the high and low molecular weight tails and relatively less in the midst of the chromatogram. This is a simple and very effective method for measuring the composition drift of copolymer materials Figure 14.

This example shows composition drift measurements of a styrene-butadiene copolymer. A peak ratio chromatogram 

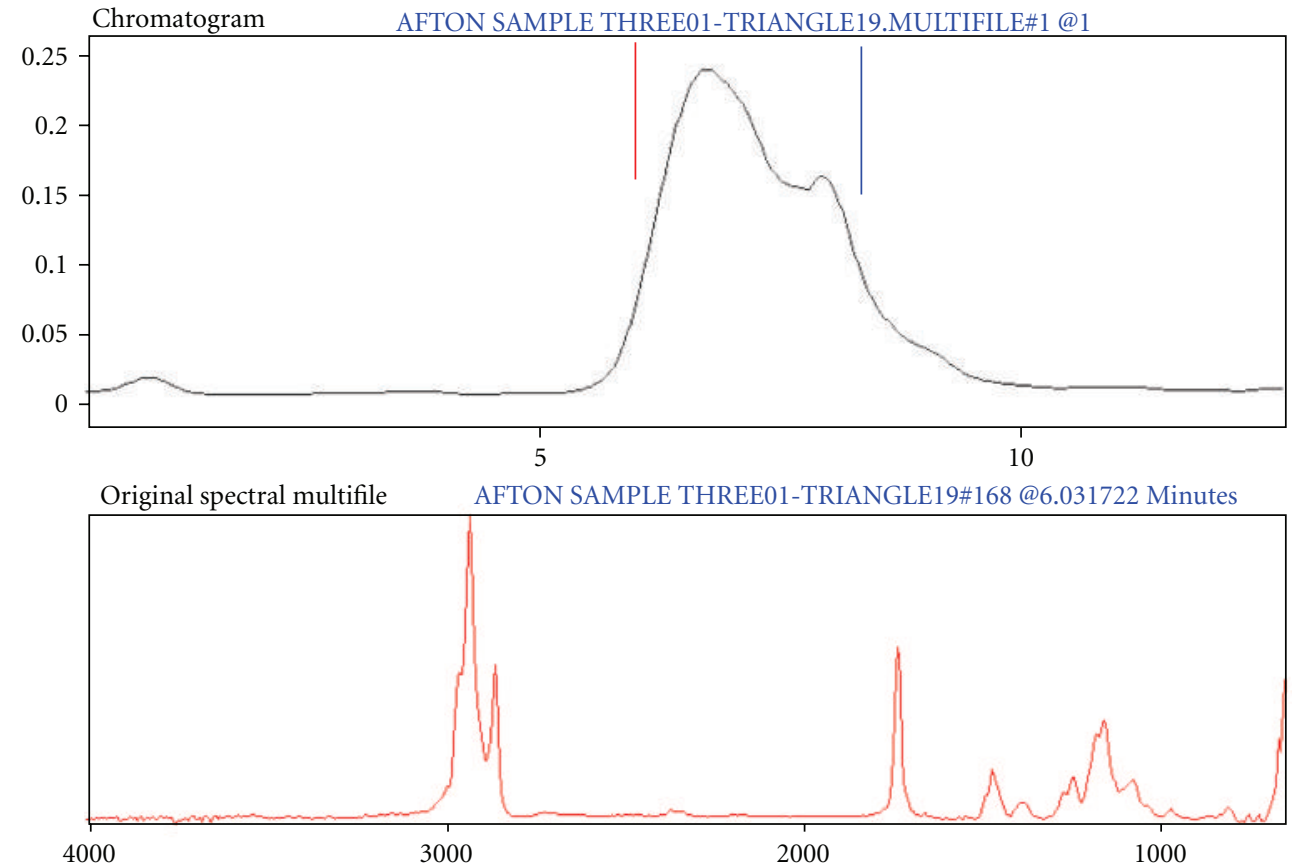

Peaks spectral multifile AFTON SAMPLE THREE01-TRIANGLE19PEAKS\#2 @8.390943 Minutes

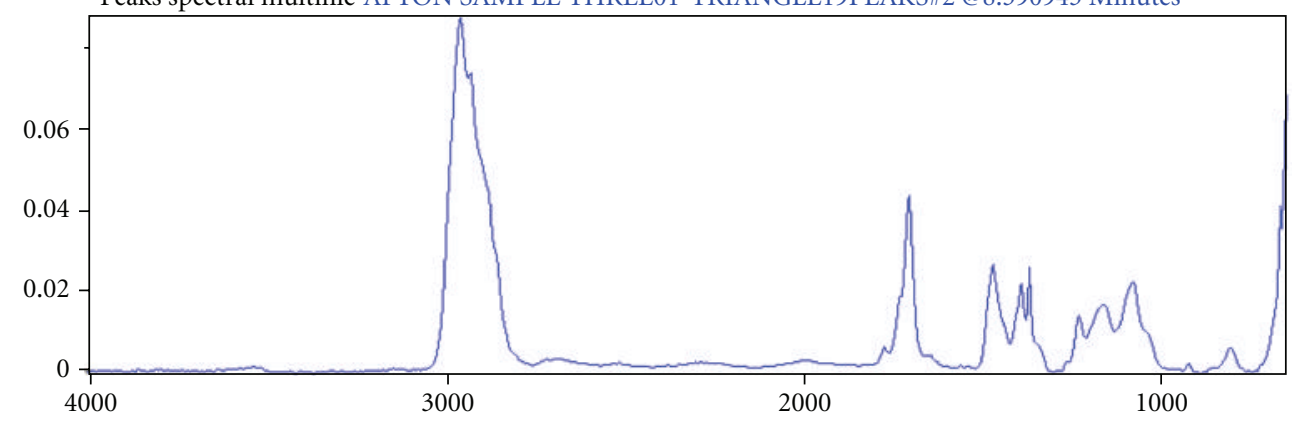

FIGURE 9: Two component polymer blend: overlapping MW distributions.

of the styrene/diene absorbance ratio was generated. The ratio chromatogram was algebraically transformed to a plot of polymer styrene content as a function of molecular weight. The $968 \mathrm{~cm}^{-1}$ (diene) and $1495 \mathrm{~cm}^{-1}$ (styrene) absorbance intensities were used for the absorbance ratio. A bulk spectrum of a known overall composition copolymer will provide the value $(k,(2))$ of extinction coefficient ratio.

\subsection{Lot-to-Lot Characterization: Composition Drift in Copoly-} mer Pharmaceutical Excipients. Polymer excipients are increasingly used to enhance and control the delivery of active pharmaceutical ingredients (APIs). They play an especially crucial role in delivery of poorly soluble drugs $[12,13]$. An oral drug must:

(i) withstand the rigors of the compounding and fabrication processes,

(ii) retain efficacy during shelf life,

(iii) make the passage through the stomach without undue decomposition, (iv) be released in the GI tract with adequate bioavailability and with a desired release kinetic profile.

Performance is achieved by control of both the chemical and physical properties of the excipient package. Both polymer blends and copolymers are used in this field.

Figure 15 demonstrates compositional drift of samples of Copovidone, a widely used pharmaceutical tablet excipient. It is a vinyl-pyrrolidone/vinyl acetate copolymer. The analytical method was similar to that used in the styrene/butadiene example. Infrared chromatograms were generated for of the total eluting polymer mass (maximum intensity infrared bands), and for infrared bands centered at $1740 \mathrm{~cm}^{-1}$ (acetate) and $1680 \mathrm{~cm}^{-1}$ (pyrrolidone). The dotted line curves are the GPC chromatograms of the total polymer mass, and the solid lines the vinyl acetate comonomer distribution. As is apparent, both the average molecular weights and compositional drift varied in the three samples, with resulting differences in performance. With the aid of calibration standards, one can transform the band ratio chromatograms to quantitative determinations of comonomer distribution (shown on the right vertical axis). 


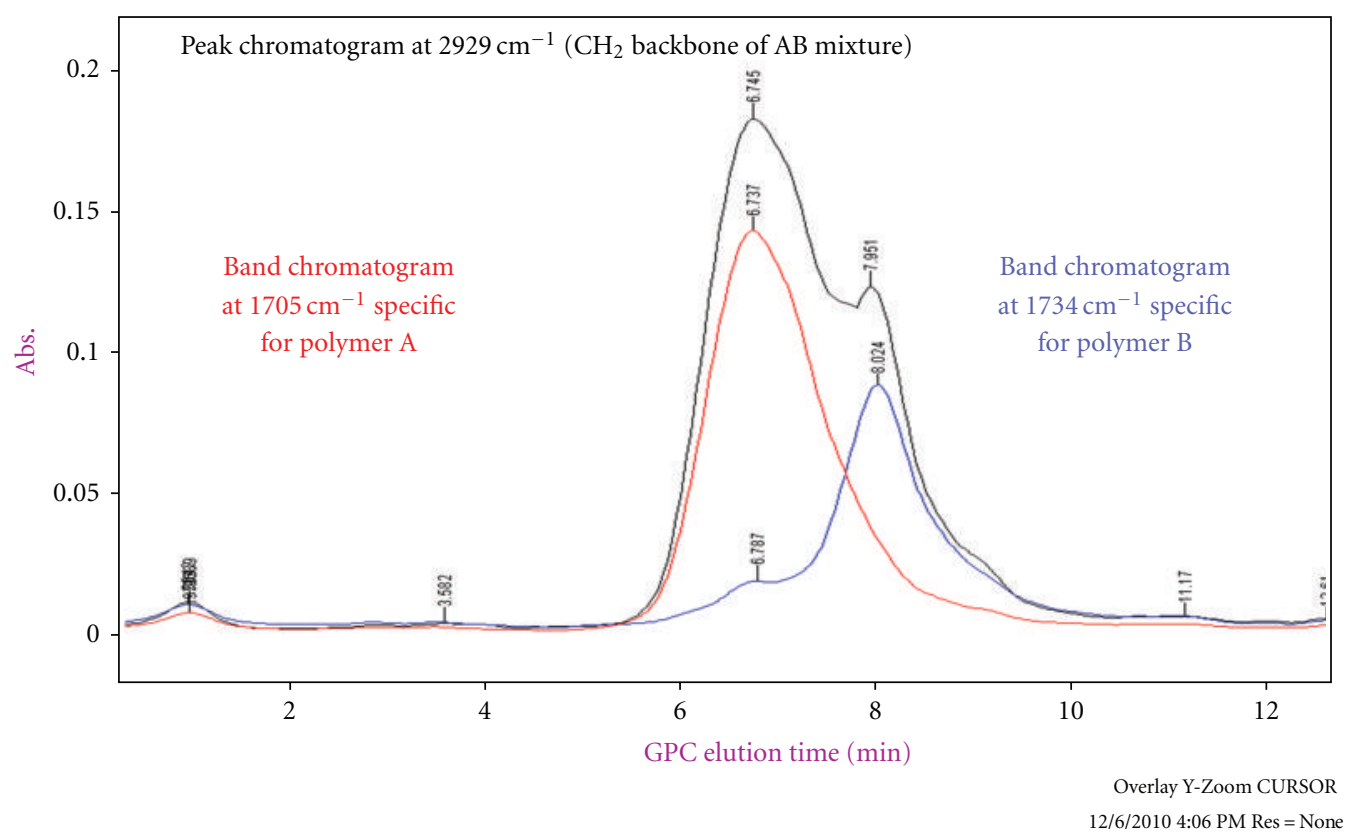

FIgURE 10: Band chromatograms showing distribution of two components.

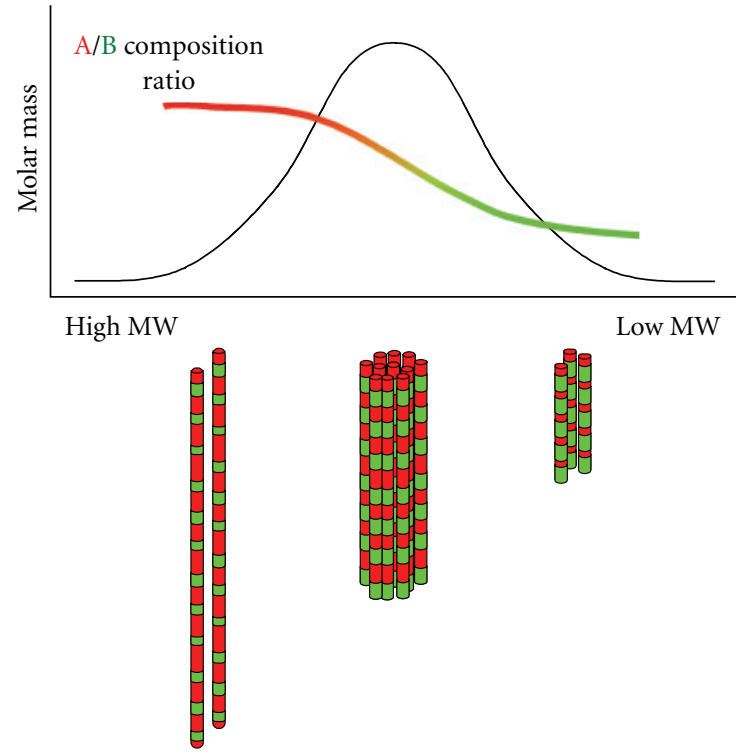

Polymer chains

Comonomer A

Comonomer B

FIGURE 11: GPC mass distribution and varying concentration of comonomers.

The polymer sample with the most variable comonomer distribution showed problems in end-use performance.

\subsection{Utilization of Configuration/Conformation Artifacts.}

Infrared spectrometry not only reveals the composition functional groups (esters, ethers, nitriles, amides, and silicones), present in a

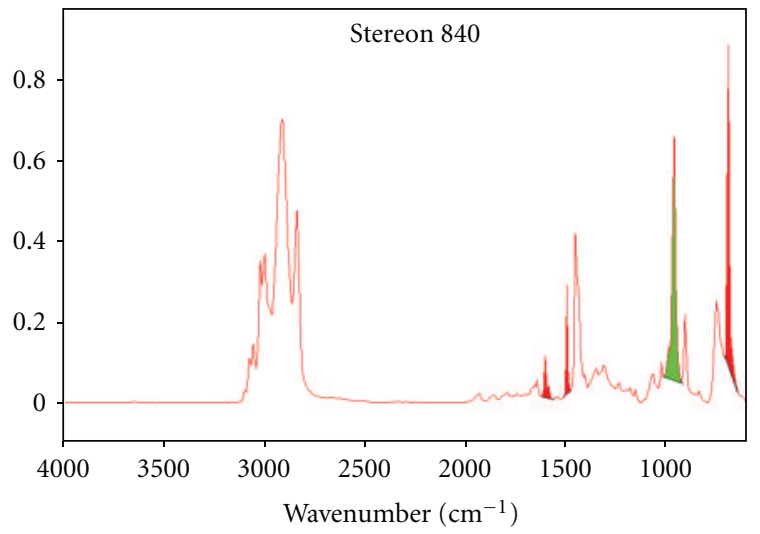

FIGURE 12: Bulk spectrum of a styrene/butadiene copolymer.

polymer, but also configuration and conformation properties such as stereoisomers, cis-trans configurations, crystallinity, and stereoregularity.

The following analysis of polyolefins shows how conformational spectral bands can aid in the deformulation of olefin polymers.

There are many commercially available polyolefin polymers, and they have a broad range of physical performance attributes. Polyolefins can be synthesized as high modulus structural materials, soft rubbers, and most everything in between. They are made chiefly from the monomers ethylene and propylene and possess only carbon and hydrogen atoms.

Polyolefins are, by definition, constituted of only carbon and hydrogen. Principal bands are limited. At first glance, vibrational spectroscopy might seem to be of scant utility, 


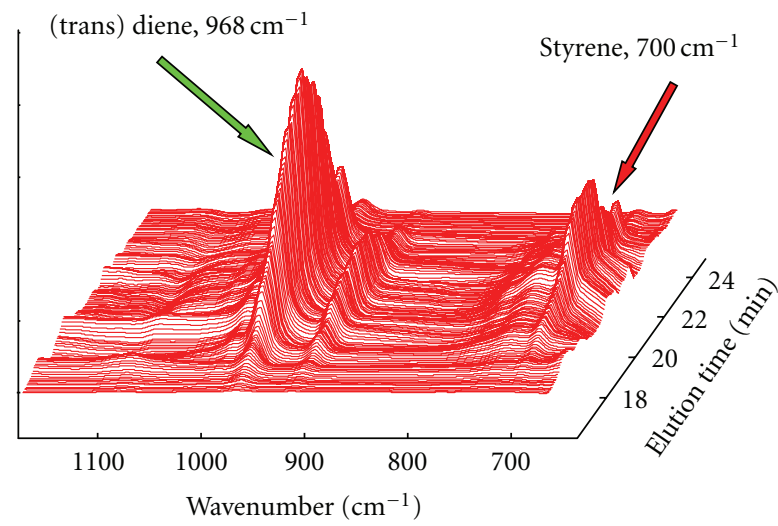

FIGURE 13: GPC-IR data map of SBR copolymer.

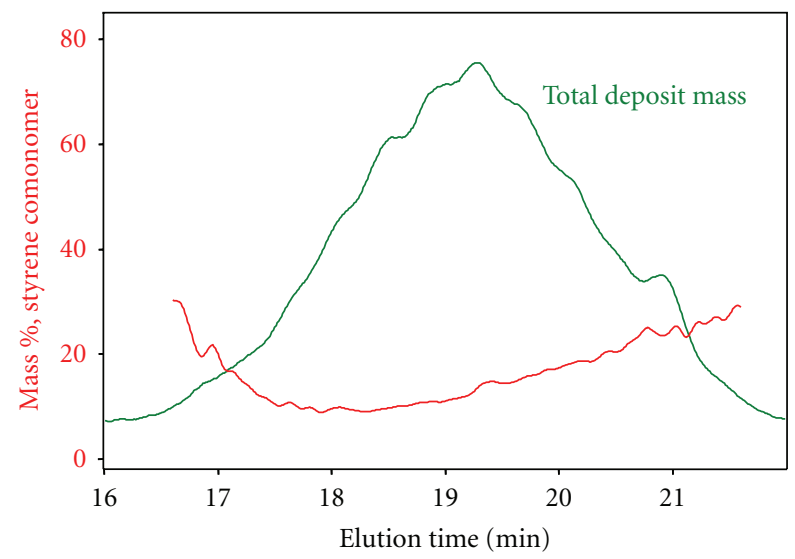

Figure 14: Band chromatograms of the comonomers butadiene and styrene.

but the configuration/conformation properties of olefin polymers make infrared spectroscopy possibly the most useful tool available for characterization. It is also the configuration/conformation properties that determine many of the physical properties of a polyolefin.

Three samples of olefin polymers were analyzed by GPCFTIR. Referring to Figure 16, we see the following.

Sample 1 is polypropylene homopolymer.

Sample 2 is an ethylene propylene copolymer.

Sample 3 is determined to be a blend of polypropylene homopolymer, ethylene/propylene copolymer, and ethylene/butene copolymer.

The sample was analyzed for molecular and composition drift as in the previous examples. For brevity, the molecular weight distributions of composition and composition drift are not repeated here. This example points out the composition and configuration aspects used to characterize Sample 3.

(i) The $720 \mathrm{~cm}^{-1}$ evidences some splitting, suggesting crystallinity in long sequences of ethylene comonomer.

(ii) The 1155 band is a methyl branch band of polypropylene and is common to all samples.

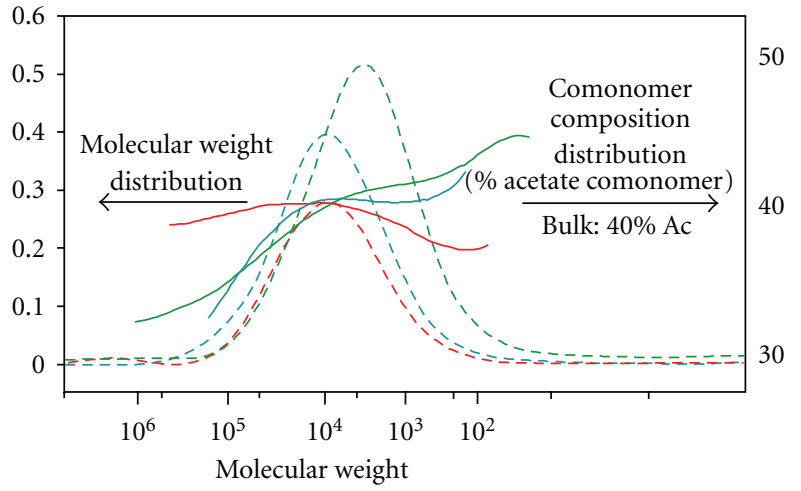

Copovidone:

- Sample A

- Sample B

- Sample C

FIGURE 15: Compositional drift variations in a pharmaceutical excipient.

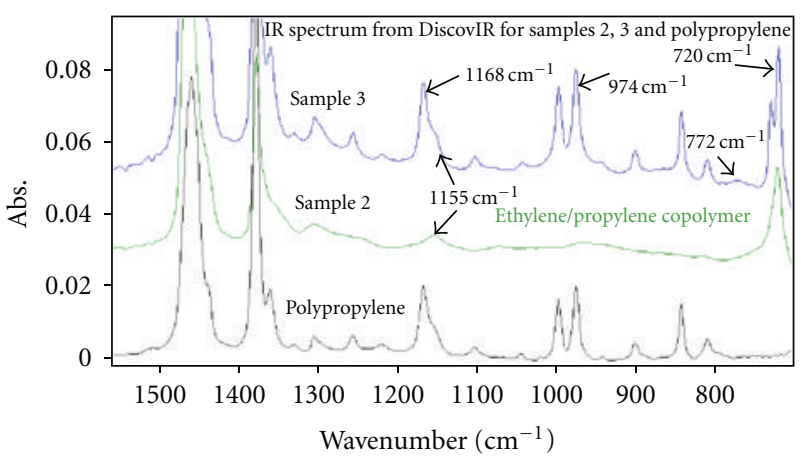

FIGURE 16: IR spectra of three polyolefin products.

(iii) The presence of the $772 \mathrm{~cm}^{-1}$ indicates the butene comonomer in Sample 3. This is supported by similar elution chromatograms (not shown) of the $720 \mathrm{~cm}^{-1}$ and $772 \mathrm{~cm}^{-1}$ bands.

(iv) The ethylene/propylene, by contrast, shows no such peak splitting. This infers that the peak splitting arises from long ethylene sequences of ethylene comonomer in the ethylene/butene copolymer.

(v) Sample 1 is an isotactic polypropylene, as evidenced by the $1168 \mathrm{~cm}^{-1}$ band. Sample 2 is atactic. The presence of the isotactic PP band in sample 3 arises from the blend of sample 2 and sample 1.

4.7. Aging/Environmental Changes: Polymer Synthesis and Degradation Problems. Polyethylene glycol (PEG) is a polyether terminated with hydroxyl groups. It is a low molecular weight polymer with the depicted structure

$$
\mathrm{H}-\left(\mathrm{OCH}_{2} \mathrm{CH}_{2}\right)_{n}-\mathrm{OH}
$$

Polyethylene glycol is widely used in both consumer products and medicinal formulations. In medical applications, PEG is used as a protective molecule for active ingredients. "PEGylation" of proteins (bonding of active ingredient 


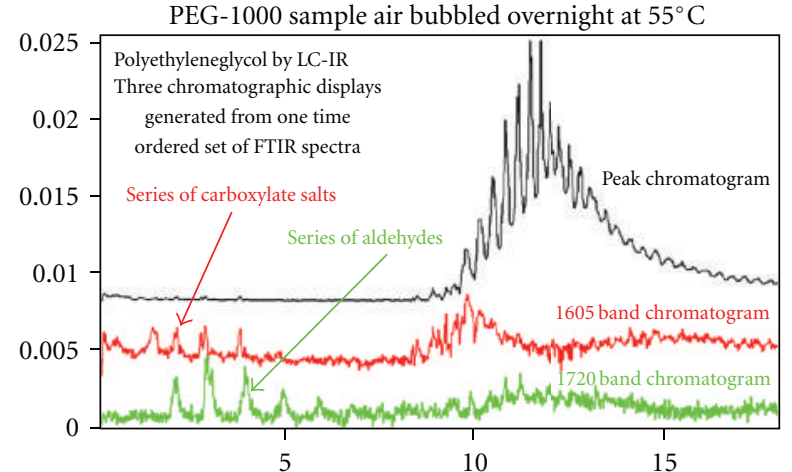

Figure 17: Oxidative changes of Polyethylene glycol.

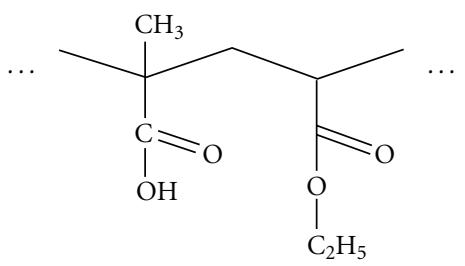

FIGURE 18: Eudragit backbone molecular structure.

proteins to PEG) is used modify the biological uptake of the protein. In formulations, PEG is also used to modify the absorption of ingested medications (Figure 17).

In such applications, degradation of the PEG can have an adverse effect on the shelf life or potency of the medication.

After the oxidation process, the bulk material showed weak IR bands at $1720 \mathrm{~cm}^{-1}$ and $1640 \mathrm{~cm}^{-1}$, which were absent from the original PEG 1000. Examination by LC-FTIR revealed two series of oxidative cleavage products: one series containing aldehyde functionality and the other a series of carboxylic acid salts, which account for the extra IR bands. This information gives insight towards preservation strategies for extending the shelf life of formulations containing PEG. RP-LC/FTIR results are shown.

Functional group chromatograms revealed a series of aldehyde and carboxylated salt oligomers produced by the oxidation process. Air oxidation of PEG generates unstable peroxides, typical of the autooxidation of ethers. The peroxides then react further, leading to cleavage of the PEG chain between oxygen and carbon atoms.

The resulting aldehydes and carboxylate salts are PEG oligomers with oxidized end groups. Both of these more polar series elute early in the reverse-phase chromatogram. The bulk material shows the carboxylate IR band at 1640, consistent with a tightly bound cation such as a transition metal. This suggests a cleanup technique for preservation of the bulk material to improve the shelf life of products containing PEG.

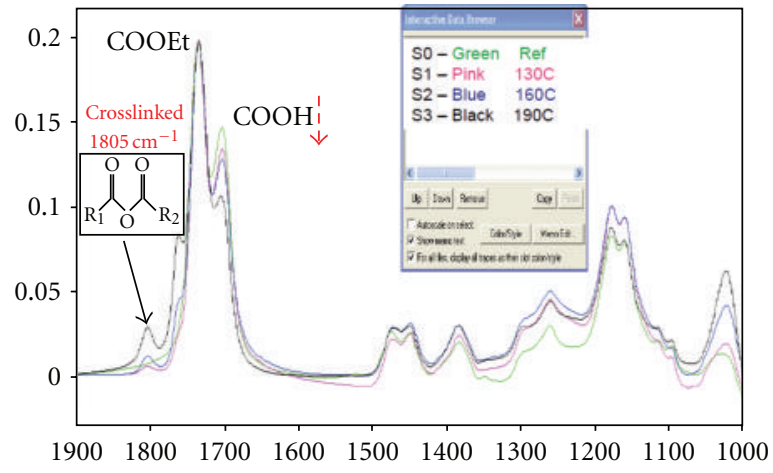

FIGURE 19: Undesired cross-linking of a pharmaceutical polymeric excipient.

In a similar vein, Figure 19 shows the thermally induced crosslinking of a pharmaceutical excipient which is coextruded with an active pharmaceutical ingredient.

4.8. Thermally Induced Crosslinking of Pharmaceutical Excipient. Eudragit L100-55 excipient is a copolymer with the polymer backbone structure as shown in Figure 18.

Extrusion is performed at an elevated temperature. A GPC-FTIR analysis of product under various extrusion conditions revealed that a side group was cleaved from the polymer backbone, with resultant formation of anhydride cross-links. This has a deleterious effect on release characteristics of the active ingredient.

4.9. Reactive Systems Analysis: Paints and Coatings. Many coatings are based on chemical reaction for their "drying" or "curing". Epoxy and urethane systems are examples of liquid polymer materials that treat to form hard films or objects.

Oil-based paints are the most ubiquitous of reactive coatings. Paints consist of polymers dissolved in oils such as linseed oil, soya oil, and various vegetable oils. These oils are unsaturated fatty acids, and they have the ability to form adducts with the polymer component under appropriate reaction conditions.

During the coating synthesis, some portions of the vegetable oil will become adducted to the polymer mass. Upon exposure to oxygen, these unsaturates will cross-link to form a solid film (drying).

Figure 20 shows the use of GPC-FTIR to determine the degree of adduction of a paint oil vehicle into the polymer component of the paint. The blue chromatogram is generated by the ester carbonyl of the vehicle. The monomeric oil shows an elution peak centered at 32 minutes. The early eluting portion of carbonyl functionality (20$31 \mathrm{~min}$ ) is bound to the polymer mass, and this adduct has a higher molecular weight (and earlier elution time) than the monomer.

To make a quantitative assessment of monomer-polymer partitioning of the oil, the area under the carbonyl IR chromatogram was integrated, and a judgment was made as to the polymer/monomer partition (ca. 31 minutes). 


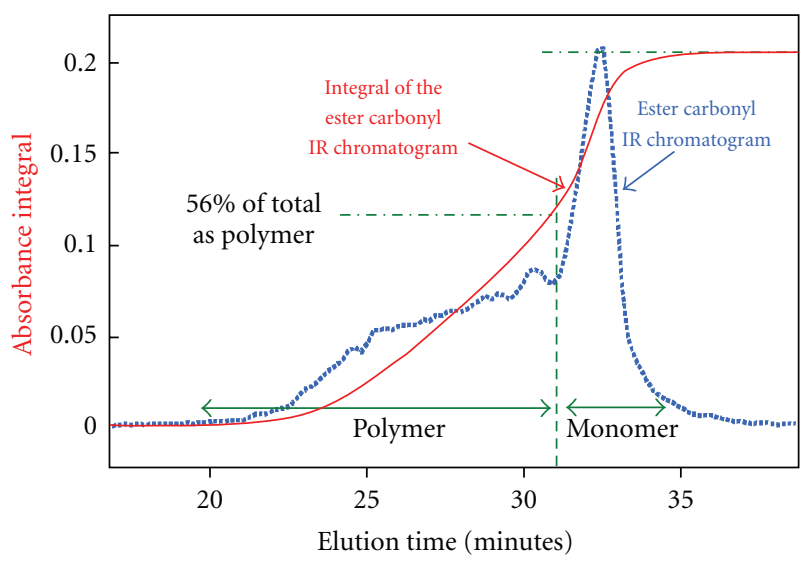

FIgURE 20: Paint: partitioning of oil into the polymer fraction.

Scalar values of the integral function were taken at this time and at the maximum of the integral curve, resulting in a determination of $56 \%$ inclusion of the oil into the polymer mass.

This is a postreaction end state analysis of the sample. The technique can be extended to monitoring real-time reaction kinetics of processes whose total reaction times are greater than one hour. The limiting factor is the cycle time of the chromatography column.

\section{Experimental Conditions for Described Applications}

(4.1) Deformulation: Analysis of Lubricant Polymeric Additives.

$\begin{array}{ll}\text { Sample } & \text { Shell rotella T SAE } \\ \text { Chromatography } & 15 \mathrm{~W}-40 \text { diesel engine oil } \\ \text { Column } & \text { GPC: Jordi mixed bed: } \\ & 25 \times 1 \mathrm{~cm} \\ \text { Mobile phase } & \text { Tetrahydrofuran (THF) } \\ \text { Flow rate } & 50 \mu \mathrm{mL} / \mathrm{min} \\ \text { Injection volume } & 90 \mathrm{mg} / \mathrm{mL} \\ \text { Sample concentration } & \\ \begin{array}{l}\text { Deposition and spectrometry } \\ \text { Cyclone temperature }\end{array} & 260^{\circ} \mathrm{C} \\ \begin{array}{l}\text { Pressure, Cyclone } \\ \text { Pressure, sample deposit } \\ \text { chamber }\end{array} & 400 \mathrm{torr} \\ \text { Carrier gas flow } & 6.4 \text { torr } \\ \text { Condenser temp } & 380 \mathrm{cc} / \mathrm{min} \\ \text { Zn Se disk translation rate } & 3 \mathrm{~mm} / \mathrm{min} \\ \text { Disk temp } & 20^{\circ} \mathrm{C} \\ \text { Nebulizer power } & 6 \mathrm{Watts}\end{array}$

(4.3) Overlapping IR Chromatograms of Polymer Blends.

$\begin{array}{ll}\begin{array}{l}\text { Sample } \\ \text { Chromatography }\end{array} & \text { Polymer blend } \\ \text { Column } & \text { GPC: waters styragel HR } \\ \text { Mobile phase } & 4 \\ \text { Flow rate } & \text { Tetrahydrofuran (THF) } \\ \text { Injection volume } & 1 \mathrm{~mL} / \mathrm{min} \\ \text { Sample concentration } & 100 \mu \mathrm{L} \\ \text { Deposition and spectrometry } & 3 \mathrm{mg} / \mathrm{mL} \\ \text { Cyclone temperature } & \\ \text { Pressure, cyclone } & 150^{\circ} \mathrm{C} \\ \text { Pressure, sample deposit } & 369 \text { torr } \\ \text { chamber } & 4.7 \mathrm{torr} \\ \text { Carrier gas flow } & 380 \mathrm{cc} / \mathrm{min} \\ \text { Condenser temp } & 15^{\circ} \mathrm{C} \\ \text { Zn Se disk translation rate } & 3 \mathrm{~mm} / \mathrm{min} \\ \text { Disk temp } & 0^{\circ} \mathrm{C} \\ \text { Nebulizer power } & 5 \mathrm{Watts}\end{array}$

(4.4) Copolymers: Composition Drift.
Sample

Chromatography

Column

Mobile phase

Flow rate

Injection volume

Sample concentration

Deposition and spectrometry

Cyclone temperature

Pressure, cyclone

Pressure, sample deposit

chamber

Carrier gas flow

Condenser temp

Zn Se disk translation rate

Disk temp

Nebulizer power
Firestone 721AC styrene/butadiene copolymer

GPC: Jordi $50 \times 1 \mathrm{~cm}$ mixed bed: linear DVB Tetrahydrofuran (THF) $1 \mathrm{~mL} / \mathrm{min}$

$5 \mu \mathrm{L}$

$12 \mathrm{mg} / \mathrm{mL}$

$248^{\circ} \mathrm{C}$

400 torr

5.8 torr

$321 \mathrm{cc} / \mathrm{min}$

$-10^{\circ} \mathrm{C}$

$3 \mathrm{~mm} / \mathrm{min}$

$90^{\circ} \mathrm{C}$

1 Watt
(4.5) Lot to Lot Characterization: Composition Drift in Copolymer Pharmaceutical Excipients. The chromatograph used in this application was a Waters $150^{\circ} \mathrm{C}$ chromatograph, operating at $145^{\circ} \mathrm{C}$. 


\begin{tabular}{|c|c|}
\hline Sample & $\begin{array}{l}\text { Copovidone (BASF } \\
\text { Kollidon VA64) }\end{array}$ \\
\hline \multicolumn{2}{|l|}{ Chromatography } \\
\hline Column & $\begin{array}{l}\text { Shodex OHpak } \\
\text { SB-806 M HQ }\end{array}$ \\
\hline Mobile phase & $\begin{array}{l}\mathrm{MeOH} / \mathrm{H}_{2} \mathrm{O}, 0.05 \mathrm{M} \\
\text { acetic acid }\end{array}$ \\
\hline Flow rate & $1 \mathrm{~mL} / \mathrm{min}$ \\
\hline Injection volume & $150 \mu \mathrm{L}$ \\
\hline Sample concentration & $0.35 \%$ \\
\hline \multicolumn{2}{|l|}{ Deposition and spectrometry } \\
\hline Cyclone temperature & $21^{\circ} \mathrm{C}$ \\
\hline Pressure, cyclone & 750 torr \\
\hline $\begin{array}{l}\text { Pressure, sample deposit } \\
\text { chamber }\end{array}$ & 2.6 torr \\
\hline Carrier gas flow & $0 \mathrm{cc} / \mathrm{min}$ \\
\hline Condenser temp & $20^{\circ} \mathrm{C}$ \\
\hline Zn Se disk translation rate & $3 \mathrm{~mm} / \mathrm{min}$ \\
\hline Disk temp & $25^{\circ} \mathrm{C}$ \\
\hline Nebulizer power & 0 Watts \\
\hline
\end{tabular}

(4.6) Utilization of Configuration/Conformation Artifacts. A sample of PEG 1000 (polyethylene glycol of average molecular weight 1000) was subjected to vigorous air oxidation and then analyzed it by reverse-phase LC-IR to learn about the identity and distribution of the oxidation products within the bulk polymer.

$\begin{array}{ll}\begin{array}{ll}\text { Sample } \\ \text { Chromatography }\end{array} & \text { Blend of polyolefins } \\ \text { Column } & \begin{array}{l}\text { GPC: Jordi DVB mix } \\ \text { bed } 25 \mathrm{~cm} \times 1 \mathrm{~cm}, 5 \mu \mathrm{m} \\ 1,2,4 \text { trichlorobenzene } \\ \text { (TCB) }\end{array} \\ \text { Mobile phase } & 1 \mathrm{~mL} / \mathrm{min} \\ \text { Flow rate } & 100 \mu \mathrm{L} \\ \text { Injection volume } & 25 \mathrm{mg} / \mathrm{mL} \\ \text { Sample concentration } & \\ \begin{array}{l}\text { Deposition and spectrometry } \\ \text { Cyclone temperature }\end{array} & 375^{\circ} \mathrm{C} \\ \text { Pressure, cyclone } & 109 \mathrm{torr} \\ \text { Pressure, sample deposit } & 1 \mathrm{torr} \\ \text { chamber } & 57 \mathrm{cc} / \mathrm{min} \\ \text { Carrier gas flow } & 20^{\circ} \mathrm{C} \\ \text { Condenser temp } & 3 \mathrm{~mm} / \mathrm{min} \\ \text { Zn Se disk translation rate } & 90^{\circ} \mathrm{C} \\ \text { Disk temp } & 10 \mathrm{Watts} \\ \text { Nebulizer power } & \end{array}$

(4.7) Aging/Environmental Changes: Polymer Synthesis and Degradation Problems.

Sample

Chromatography

Column

Mobile phase

Flow rate

Injection volume

Sample concentration

Deposition and

spectrometry

Cyclone temperature

Pressure, cyclone

Pressure, sample deposit

chamber

Carrier gas flow

Condenser temp

Zn Se disk translation rate

Disk temp

Nebulizer Power
Polyethylene glycol (PEG 1000 ), partially air oxidized in $15 \%$ acetonitrile/water

Reverse-phase eclipse C-18, $4.6 \times 50 \mathrm{~mm}$

$10-90 \%$ acetonitrile gradient, $30 \mathrm{~min}$

$1 \mathrm{~mL} / \mathrm{min}$

$150 \mu \mathrm{L}$

$4.5 \mathrm{mg} / \mathrm{mL}$

$180^{\circ} \mathrm{C}$

460 torr

5.2 torr

$370 \mathrm{cc} / \mathrm{min}$

$5^{\circ} \mathrm{C}$

$3 \mathrm{~mm} / \mathrm{min}$

$-20^{\circ} \mathrm{C}$

13.5 Watts

(4.8) Thermally Induced Crosslinking of Pharmaceutical Excipient.

Sample

Chromatography

Column

Mobile phase

Flow rate

Injection volume

Sample concentration

Deposition and

spectrometry

Cyclone temperature

Pressure, cyclone

Pressure, sample deposit

chamber

Zn Se disk translation

rate

Disk temp

\section{Summary}

The multidistributed attributes of polymer systems present a huge challenge to the analyst. Infrared spectrometry has proved to be a superior tool in polymer analysis, but is 
severely limited by the multicomponent nature of polymer samples. Traditional sample fractionation followed by FTIR analysis can yield results but is extremely costly on terms of time and effort.

The advent on practical LC-FTIR technology addresses this need. It is suited to multiple applications for the analysis and characterization of polymer materials. Several examples of utility are presented in this paper. The combination of LC-FTIR instrumentation coupled with the interpretative capabilities of infrared software greatly assists in the interpretative aspects of infrared spectra and renders hyphenate LC-FTIR a practical working technique for polymer scientists and synthesis chemists.

\section{References}

[1] J. L. Koenig, Spectroscopy of Polymers, American Chemical Society, Washington, DC, USA, 1991.

[2] L. Coulier, E. Kaal, and T. Hankemeier, "Hyphenation of infrared spectroscopy to liquid chromatography for qualitative and quantitative polymer analysis: degradation of poly(bisphenol A)carbonate," Journal of Chromatography A, vol. 1130, no. 1, pp. 34-42, 2006.

[3] J. J. Gagel and K. Biemann, "The continuous infrared spectroscopic analysis of reversed phase liquid chromatography separations," Microchimica Acta, vol. 95, no. 1-6, pp. 185-187, 1988.

[4] K. Biemann and J. J. Gagel, "Method and apparatus for continuous collection of chromatographic effluent US Patent 4,843,243," 1989.

[5] P. R. Griffiths, K. L. Norton, and J. Andrew, "A unified approach to the chromatography-FTIR interface: GC-FTIR, SFC-FTIR, and HPLC-FTIR with subnanogram detection limits," Lange Microchemical Journal, vol. 46, no. 3, pp. 261270, 1992.

[6] A. Dekmesian, "Method and apparatus for collecting samples for analysis of chemical composition US Patent 5039614," 1991.

[7] Ibid. 1, p2.

[8] J. Schiers and D. Priddy, Modern Styrenic Polymers: Polystyrenes and Styrenic Copolymers, Wiley Series in Polymer Science, 2003.

[9] J. M. Asua, Ed., Polymer Reaction Engineering, WileyBlackwell, New York, NY, USA, 2007.

[10] J. Benkoski, G. Fredrickson, and E. Kramer, "The effects of composition drift on random copolymer reinforcement of polymer-polymer interfaces," in Proceedings of the Annual March Meeting, Washington State Convention Center Seattle, Seattle, Wash, USA, March 2001, Washington Meeting ID: MAR01, abstract \#C19.004.

[11] R. D. Mathis, Modern Plastics Encyclopedia, McGraw-Hill, New York, NY, USA, 1988.

[12] Drug Delivery Technology, vol. 8, 2008.

[13] H. Folttman and A. Quadir, "Copovidone-a copolymer with unique formulation properties," Drug Delivery Technology, vol. 8 , no. 8, pp. 22-27, 2008. 


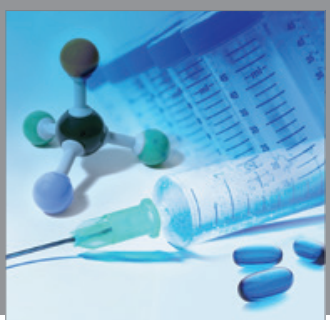

International Journal of

Medicinal Chemistry

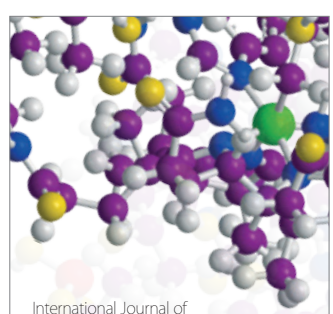

Carbohydrate Chemistry

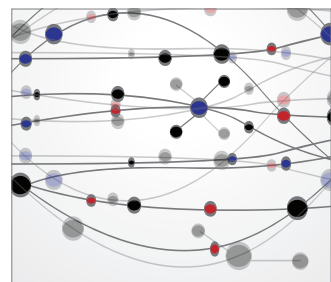

The Scientific World Journal
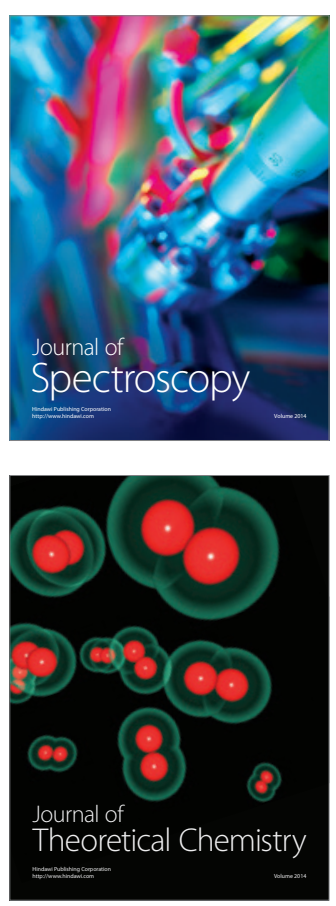
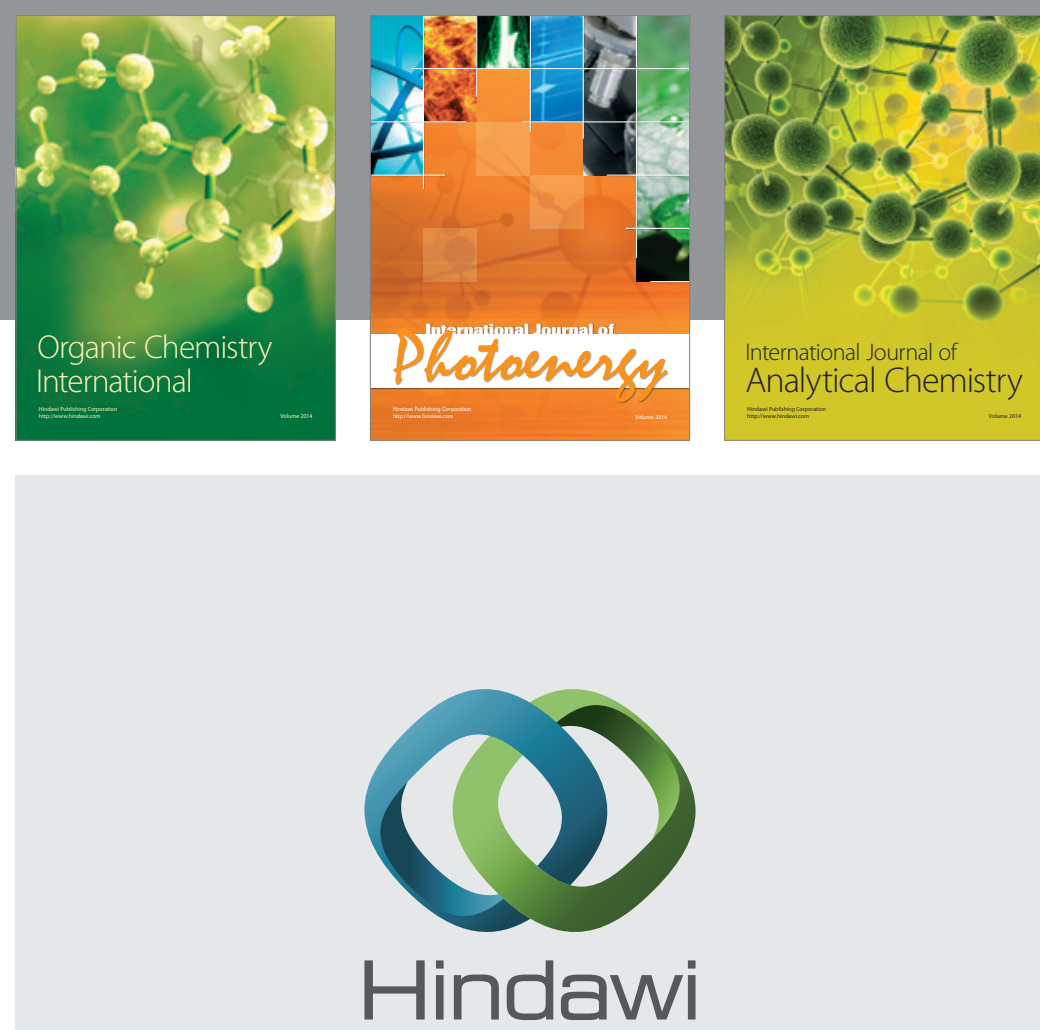

Submit your manuscripts at

http://www.hindawi.com
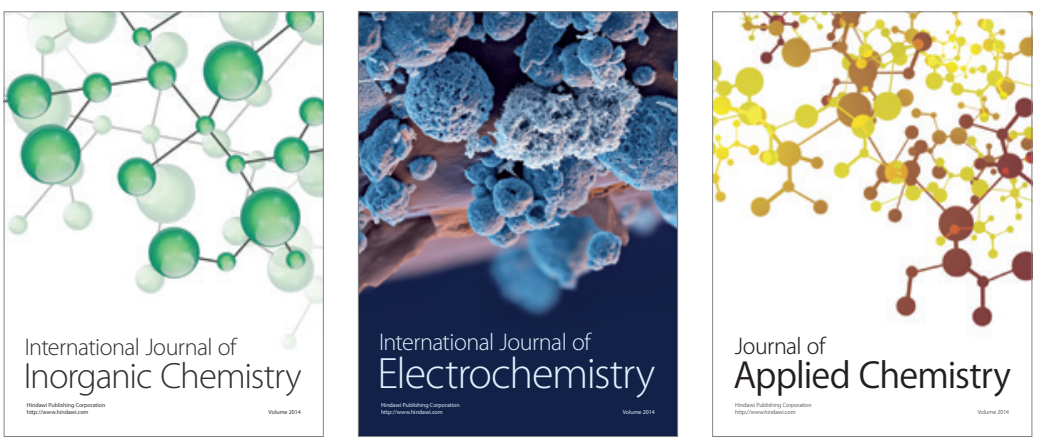

Journal of

Applied Chemistry
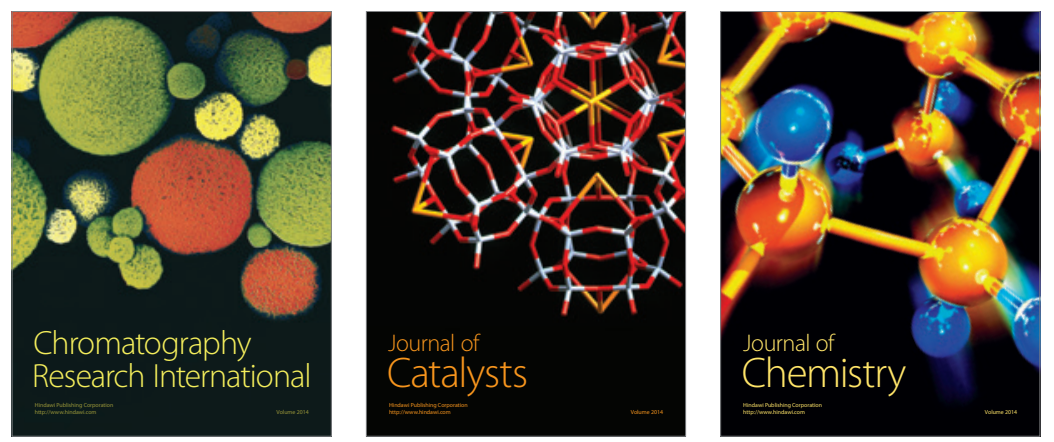
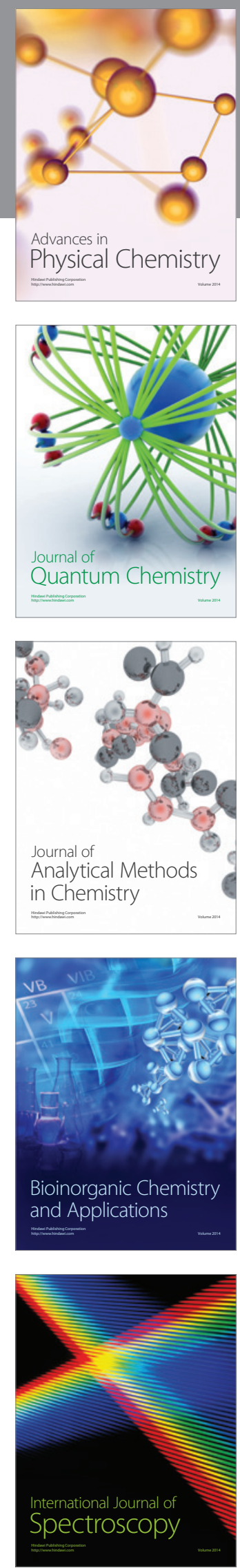